\title{
Processos de sistematização e de validação de materiais educativos nas pesquisas sobre educação na cidade
}

\author{
Dilza Côco ${ }^{1}$, Priscila de Souza Chisté Leite ${ }^{1}$ e Sandra Soares Della \\ Fonte ${ }^{2}$
}

\author{
${ }^{1}$ Instituto Federal do Espírito Santo, Brasil | dilzac@ifes.edu.br \\ https://orcid.org/0000-0001-8371-8517 | pchiste@ifes.edu.br | \\ https://orcid.org/0000-0003-2689-4180 \\ 2Universidade Federal do Espírito Santo, Brasil | sdellafonte@uol.com.br \\ |https://orcid.org/0000-0002-9514-7202
}

\begin{abstract}
Resumo: Este texto discute questões metodológicas acerca do processo de produção e de validação de materiais educativos publicados por um grupo que investiga relações entre educação e cidade (Gepech). Objetiva-se aqui examinar dados sobre o processo de validação desses materiais educativos em ações de formação continuada com professores da educação básica brasileira. Para isso, o grupo realiza pesquisa de levantamento no repositório digital Educapes e analisa dados de cinco investigações. Conclui-se que a abordagem crítica e colaborativa possibilita a estruturação de instrumentos de validação organizados por eixos temáticos que permitem, a pesquisadores e a professores da educação básica, estabelecer relações colaborativas e propositivas como modo de contribuir para o aprimoramento dos materiais educativos sistematizados.
\end{abstract}

Palavras Chave: Educação; Formação de Professores; Avaliação; Recursos educativos; Investigação Qualitativa.

\section{Introdução}

Estudos sobre a cidade apresentam-se como temática importante no campo da educação, pois contribuem para a compreensão de aspectos históricos, políticos, sociais, culturais, filosóficos e econômicos referentes ao desenvolvimento do urbano. A possibilidade de contribuir com esse nicho de pesquisa e a experiência pregressa relacionada à educação em espaços não formais favoreceram a constituição de um grupo de estudos composto por alunos e professores do Programa de Pós-Graduação em Ensino de Humanidades do Instituto Federal do Espírito Santo (Ifes), Brasil. Ao partir da compreensão de Educação na Cidade pela via da emancipação humana, o Grupo de Estudos e Pesquisas sobre Educação na Cidade e Humanidades (Gepech) entende que a cidade nos seus espaços e tempos imprime uma orientação pedagógica. Desse modo, a Educação na Cidade (Côco, Chisté, \& Della Fonte, 2018) configura-se como uma abordagem que busca promover a leitura do urbano por meio do desvelamento de conflitos e contradições presentes na materialidade citadina. Ao considerar tais proposições, o Gepech se estrutura a partir de ações como encontros de estudos teóricos que têm como referência obras de autores da linha crítica; diálogos com palestrantes convidados de diferentes áreas que possuem vinculação com os estudos da cidade; realização e exibição de entrevistas com estudiosos de projeção nacional; e visitas mediadas a espaços (praças, monumentos, parques, praias, ruas e museus) e exposições de arte com o objetivo de ampliar os conhecimentos sobre a cidade, com destaque para Vitória, no Estado do Espírito Santo; elaboração de materiais educativos e promoção de cursos para professores para compartilhar as pesquisas e validar as produções realizadas. Em meio a este contexto, este capítulo apresenta um recorte das investigações realizadas pelo Gepech, com foco na produção e avaliação de materiais educativos elaborados em pesquisas de mestrado profissional na área de ensino. Nesse sentido, objetivamos examinar dados sobre o processo de produção e validação desses materiais educativos em ações de formação continuada com professores da educação básica brasileira. 
As metodologias de pesquisa utilizadas foram o levantamento bibliográfico, quanto ao estudo de dissertações de mestrado; e a pesquisa colaborativa (Ibiapina, 2008), tendo em vista as formações de professores e as validações de materiais educativos que nelas ocorreram.

Como modo de organizar este texto, iniciaremos ao apresentar o referencial teórico que orienta a produção de materiais educativos (Kaplún, 2002, 2003; Ruiz, Motta, Bruno, Demonte \& Tufré, 2014) e, na sequência, explicaremos como se dá a produção de materiais educativos em nosso grupo, bem como o modo como avaliamos tais materiais no contexto da formação de professores da educação básica brasileira. Salientamos que esse processo de avaliação sustenta-se também nos estudos de Leite (2019).

\section{O referencial teórico}

A produção de materiais educativos é um tema muito caro à Educação Popular (Brandão, 1984) no contexto da América Latina. Visa, sobretudo, à conscientização das camadas populares acerca de um tema. Kaplún $(2002,2003)$ aponta que materiais educativos são objetos facilitadores da experiência de aprendizado, cuja elaboração requer pesquisa temática (conhecer o assunto com profundidade), pesquisa diagnóstica (conhecer o que autores conceituados dizem sobre o tema) e também pesquisa pedagógica (estimular as discussões e mudanças na prática pedagógica por meio da criação de situações de aprendizagem junto a alunos). Kaplún $(2002,2003)$ propõe que a produção de materiais educativos seja orientada por três eixos temáticos, conforme Quadro 1.

Quadro 1. Eixos temáticos para produção de materiais educativos (Kaplún, 2002).

\begin{tabular}{l|l}
\hline \multirow{2}{*}{$\begin{array}{l}\text { Eixo } \\
\text { conceitual }\end{array}$} & $\begin{array}{l}\text { Refere-se à escolha das ideias centrais } \\
\text { abordadas pelo material, bem como temas } \\
\text { principais geradores de experiências de } \\
\text { aprendizado. }\end{array}$ \\
\hline $\begin{array}{l}\text { Eixo } \\
\text { pedagógico }\end{array}$ & $\begin{array}{l}\text { Expressa o percurso que será oferecido ao } \\
\text { leitor. Implica conhecer os sujeitos a quem se } \\
\text { destina o material para entender o que sabem } \\
\text { sobre o tema e quais necessidades poderiam } \\
\text { ser respondidas pelo material. }\end{array}$ \\
\hline $\begin{array}{l}\text { Eixo } \\
\text { comunicacio }\end{array}$ & $\begin{array}{l}\text { Diz respeito ao formato, diagramação e } \\
\text { linguagem empregada no material educativo. }\end{array}$ \\
\hline
\end{tabular}

Sobre a validação de materiais educativos, Kaplún (2003) aponta que uma possibilidade seria partir de práticas pedagógicas concretas, ou seja, analisar o material em condições reais e não em uma prova de laboratório em condições artificiais. Inspirados nas propostas de Kaplún, pesquisadores argentinos elaboraram uma cartilha intitulada Producción de materiales de comunicación y educación popular (Ruiz et al., 2014) com o objetivo de oferecer ferramentas para a criação de materiais de forma participativa, respeitando os direitos humanos e a diversidade de gênero. Na cartilha, o grupo busca também apresentar possibilidades de validação participativa por meio de entrevistas individuais, coletivas ou grupos de discussão. Sugerem a organização de um guia de perguntas a partir de cinco componentes, originalmente desenvolvidos pela Academy for Educational Development (AED), a saber: atração, compreensão, envolvimento, aceitação e mudança da ação. A partir dos autores supracitados, Leite (2019) adapta tais recomendações para o campo das pesquisas desenvolvidas no contexto dos mestrados profissionais na área de ensino, sediados no Ifes, e elenca eixos de análises e descritores para avaliação de materiais educativos que explicaremos na seção 2.2, intitulada "Processos de validação de materiais educativos". 


\section{Materiais educativos no contexto das pesquisas do Gepech}

A partir desse referencial teórico-metodológico, o Gepech tem produzido e validado materiais educativos ao promover cursos que se relacionam com pesquisas do Mestrado Profissional em Ensino de Humanidades do Ifes. No Brasil, os mestrados profissionais possuem peculiaridades a despeito dos mestrados acadêmicos. A ênfase recai, em especial, na área de ensino, na melhoria das práticas docentes e na obrigatoriedade da criação de produtos educacionais que, entre outros formatos, podem ser materiais educativos. O Gepech tem desenvolvido uma série de materiais educativos virtuais (Ebooks) direcionados a professores que atuam na rede pública de ensino. Este formato foi escolhido pela possibilidade de divulgação rápida e também pelo baixo custo, já que não requer impressão. $O$ foco desses materiais é apresentar a cidade de modo crítico e pedagógico. Após a elaboração de versão preliminar por parte dos mestrandos, os materiais educativos são apresentados a grupos de professores de diferentes áreas de conhecimento (artes, geografia, história, letras, sociologia, filosofia e pedagogia) que aderem gratuitamente à formação por livre demanda, a partir de edital público de ampla divulgação. Essa etapa integra curso para professores da Educação Básica que envolve atividades, como discussão teórica, visitas mediadas à cidade, oficinas de arte e de criação de percursos de visita, estratégias de validação dos materiais educativos e apresentação, por parte dos professores cursistas, de propostas pedagógicas ou relatos de experiências. Nos limites deste texto, apresentaremos a metodologia de validação de materiais educativos, com ênfase na análise das pesquisas de Fraga, Côco e Chisté (2018), Morais e Côco (2018), Pinheiro e Chisté (2018), Pinto e Chisté (2018), e Frois e Della Fonte (2018).

\subsection{Descrição dos materiais educativos}

A produção do Gepech deve ser compreendida como um recorte de uma produção mais ampla, ou seja, inserida no conjunto dos produtos educacionais publicados pelo curso de Mestrado Profissional em Ensino de Humanidades. A produção desse curso registra 35 ocorrências no sítio virtual Educapes. Essa base de dados consiste em um repositório digital, de natureza governamental, que foi criado para reunir todas as produções técnicas de cursos de mestrado profissional do Brasil e, consequentemente, divulgá-las em âmbito nacional e internacional. A consulta realizada com o descritor "mestrado em ensino de humanidades do Ifes" mostra que até fevereiro de 2020 existem 18 produtos educacionais relacionados à linha de pesquisa "Práticas Educativas" e 12 produtos relativos à linha de pesquisa "Formação de Professores", no formato E-book. Em termos de ano de publicação, 05 materiais educativos foram publicados em 2017, 13 no ano de 2018 e 17 no ano de 2019. Os dados ainda identificam que um dos produtos educacionais assumiu formato que se aproxima do gênero documentário e as demais produções (quatro) não estavam disponibilizadas no sítio virtual.

No recorte que apresentamos neste capítulo privilegiaremos análises de cinco produções vinculadas ao Gepech e desenvolvidas no eixo dos estudos da linha Formação de Professores, publicadas em 2018, no referido repositório.

Esses cinco materiais educativos abordaram diferentes temáticas relacionadas à Educação na Cidade, mais especificamente sobre a cidade de Vitória/ES (fundada em 1551).

A escolha por essa cidade pode ser explicada por, ao menos, duas razões. A primeira porque trata-se de uma cidade que carrega em sua gênese a história dos primeiros núcleos de ocupação do Estado do Espírito Santo - Brasil. Em sua grafia urbana, inscrevem-se marcas dos conflitos e do trabalho de diferentes grupos sociais, como indígenas, colonizadores portugueses, jesuítas, africanos e imigrantes europeus.

A segunda porque os autores dos materiais educativos atuavam como profissionais nessa cidade e, assim, tinham maior facilidade para dialogar com os professores dessa região. 
Para fazer uma caracterização geral das produções do Gepech que serão analisadas, sistematizamos os dados do Quadro 2.

A partir desses dados, notamos que todos os materiais educativos realizaram cursos de extensão para subsidiar o processo de validação, além de envolverem significativo número de professores nessa avaliação.

Nota-se também recorrência no número de horas de atividades desenvolvidas nos cursos, excetuando-se apenas o curso 3.

Todos os materiais apresentam visão crítica da cidade, referencial teórico de base marxiana e não possuem finalidade restrita de expor práticas pedagógicas possíveis, mas buscam apresentar a cidade de modo crítico, ao oferecer subsídios para que cada professor elabore suas próprias propostas pedagógicas.

Nesse sentido, não consistem em manuais ou cartilhas, mas sim em uma possibilidade de trabalho com as temáticas propostas, que pode e deve ser ressignificada pelos professores em sua prática docente, tendo em vista seus diferentes projetos pedagógicos.

Outro ponto em comum refere-se à apresentação de roteiros de visita temática.

Quadro 2. Dados dos materiais educativos do Gepech

\begin{tabular}{|c|c|c|}
\hline Identificação do material educativo & $\begin{array}{l}\text { Dados de } \\
\text { registro }\end{array}$ & $\begin{array}{l}\text { Objetivo do material } \\
\text { educativo }\end{array}$ \\
\hline Material educativo 1 & $\begin{array}{l}\text { Autores: Pinto e } \\
\text { Chisté (2018) } \\
\text { Título: Educação } \\
\text { na cidade: o } \\
\text { processo de } \\
\text { modernização de } \\
\text { Vitória em } \\
\text { debate. }\end{array}$ & $\begin{array}{l}\text { Gerar reflexão sobre o } \\
\text { processo de modernização } \\
\text { da cidade e estimular o } \\
\text { debate sobre os impactos } \\
\text { das intervenções ocorridas } \\
\text { na cidade de Vitória - } \\
\text { Espírito Santo, ao longo dos } \\
\text { séculos. }\end{array}$ \\
\hline Material educativo 2 & $\begin{array}{l}\text { Autores: Pinheiro } \\
\text { e Chisté (2018) }\end{array}$ & $\begin{array}{l}\text { Apresentar o Parque } \\
\text { Moscoso, parque urbano } \\
\text { mais antigo da cidade de }\end{array}$ \\
\hline (ME2) & $\begin{array}{l}\text { Título: O parque } \\
\text { Moscoso como } \\
\text { espaço-memória } \\
\text { da cidade de } \\
\text { Vitória. }\end{array}$ & $\begin{array}{l}\text { Vitória, inaugurado em } \\
\text { 1912, estabelecendo uma } \\
\text { interface entre educação, } \\
\text { memória e cidade. }\end{array}$ \\
\hline Material educativo 3 & $\begin{array}{l}\text { Autores: Frois e } \\
\text { Della Fonte } \\
(2018)\end{array}$ & $\begin{array}{l}\text { Problematizar e criticar as } \\
\text { dinâmicas ambientais entre }\end{array}$ \\
\hline (ME3) & $\begin{array}{l}\text { Título: O entorno } \\
\text { da Vale S.A. na } \\
\text { perspectiva do } \\
\text { direito à cidade: } \\
\text { da miopia verde à } \\
\text { catarse do pó } \\
\text { preto. }\end{array}$ & $\begin{array}{l}\text { a empresa Vale S.A. } \\
\text { (mineradora multinacional) e } \\
\text { o seu entorno para inspirar } \\
\text { possibilidades educativas } \\
\text { questionadoras. }\end{array}$ \\
\hline
\end{tabular}




\begin{tabular}{|c|c|c|}
\hline Processo de validação & \multicolumn{2}{|c|}{$\begin{array}{l}\text { Curso de extensão de formação continuada } \\
\text { (curso 1) - Carga horária: } 60 \text { horas }\end{array}$} \\
\hline ME1+ME2+ME3 & \multicolumn{2}{|c|}{$\begin{array}{l}\text { Participantes: } 24 \text { professores de ensino } \\
\text { fundamental e médio atuantes na rede pública } \\
\text { de ensino da área de Humanidades. }\end{array}$} \\
\hline Material educativo 4 & $\begin{array}{l}\text { Autores: Fraga, } \\
\text { Côco e Chisté } \\
\text { (2018) }\end{array}$ & \multirow{2}{*}{$\begin{array}{l}\text { Colaborar com as práticas } \\
\text { pedagógicas de professores } \\
\text { da Educação Infantil, } \\
\text { considerando o patrimônio } \\
\text { cultural existente no bairro } \\
\text { llha de Monte Belo, espaço } \\
\text { da cidade onde a escola se } \\
\text { localiza. }\end{array}$} \\
\hline (ME4) & $\begin{array}{l}\text { Título: Educação } \\
\text { na cidade: } \\
\text { diálogos entre } \\
\text { educação infantil, } \\
\text { cidade e } \\
\text { patrimônio } \\
\text { cultural }\end{array}$ & \\
\hline \multirow{2}{*}{ Processo de validação ME4 } & \multicolumn{2}{|c|}{$\begin{array}{l}\text { Curso de extensão de formação continuada } \\
\text { (curso 2) - Carga horária: } 60 \text { horas }\end{array}$} \\
\hline & \multicolumn{2}{|c|}{$\begin{array}{l}\text { Participantes: } 5 \text { professoras da educação infantil } \\
\text { de uma unidade de ensino de Vitória-ES e uma } \\
\text { bolsista da área de Letras. }\end{array}$} \\
\hline Material educativo 5 & $\begin{array}{l}\text { Autores: Morais e } \\
\text { Côco (2018) }\end{array}$ & $\begin{array}{l}\text { Fomentar discussões sobre } \\
\text { o potencial de espaços da } \\
\text { cidade que contemplam a } \\
\text { vivência identitária do negro, } \\
\text { no Centro de Vitória, ES. }\end{array}$ \\
\hline (ME5) & \multicolumn{2}{|l|}{$\begin{array}{l}\text { Título: Educação } \\
\text { na cidade: } \\
\text { diálogos } \\
\text { possíveis para } \\
\text { explorar a } \\
\text { temática afro- } \\
\text { brasileira }\end{array}$} \\
\hline \multirow{3}{*}{ Processo de validação ME5 } & \multicolumn{2}{|c|}{$\begin{array}{l}\text { Encontro de formação continuada (curso 3) - } \\
\text { Carga horária: } 8 \text { horas }\end{array}$} \\
\hline & & \\
\hline & \multicolumn{2}{|c|}{$\begin{array}{l}\text { Participantes: } 25 \text { professores e profissionais da } \\
\text { escola de Educação de Jovens e Adultos. }\end{array}$} \\
\hline
\end{tabular}

Para detalhar a organização e etapas do processo de validação dos materiais educativos focados, na próxima seção contemplaremos alguns dados que apontam possibilidades metodológicas desenvolvidas pelo Gepech. 


\subsection{Processos de validação de materiais educativos}

O processo de produção de materiais educativos desenvolvido pelo Gepech pode ser dividido em quatro grandes etapas: sistematização, validação, reelaboração das propostas e divulgação do material educativo.

- A primeira etapa privilegia a investigação do objeto de estudo, contemplando pesquisas empíricas e estudos teóricos e bibliográficos, voltados para a elaboração do conteúdo do material educativo, em sua versão preliminar. Para isso, realiza-se levantamento de fontes que discutem o objeto e oferecem novos elementos de compreensão da temática. Além disso, dedica-se atenção quanto à forma, como o design do material educativo, o uso de cores e imagens, tamanho de letra, utilização de linguagem adequada ao público alvo, dentre outros elementos sinalizados por Kaplún $(2002,2003)$.

- Já a segunda etapa refere-se à ação de formação de professores. Ela é essencial para verificar a viabilidade das propostas no contexto escolar e adesão/aceitação do público alvo. Envolve a organização dos cursos, ao abarcar diferentes estratégias para que os professores enunciem suas impressões, críticas, elogios, dúvidas e problematizações. Conta-se com variadas formas de registros desses dados, como gravações de áudio e vídeo, fotografias, registros escritos, enunciados orais e questionários. Assim, o pesquisador poderá recorrer a diferentes registros para conhecer a avaliação do público alvo e qualificar o processo de validação da proposta. Essa etapa compreende também a escuta sensível por parte do pesquisador, que observa, interage e valoriza os detalhes diante desse acervo de dados.

- A terceira etapa envolve a reelaboração do conteúdo e da forma do produto a partir das sugestões dadas na etapa anterior, visando a publicação da última versão do material educativo.

- A quarta etapa envolve a divulgação do material educativo em plataformas virtuais.

Para compreensão de como este processo foi realizado, apresentaremos dados das pesquisas listadas no Quadro 2 ao exibirmos exemplos dos instrumentos utilizados (Formulários), tendo em vista os eixos e descritores elencados por Leite (2019).

A autora apresenta cinco eixos que pretendem abarcar reflexões sobre: (1) Estética e organização do material educativo; (2) Capítulos do material educativo; (3) Estilo de escrita apresentado no material educativo; (4) Propostas didáticas apresentadas no material educativo; (5) Criticidade apresentada no material educativo.

Quanto aos descritores em cada eixo, Leite (2019) sugere que eles sejam elaborados sob a forma de pergunta, a partir das especificidades estruturais e conteudísticas de cada material.

Pontua também na necessidade de dimensionar cada descritor a partir de: Atendido, Atendido Parcialmente e Não atendido, importando também destinar espaço para escrita de sugestões que ampliem a avaliação dos pontos específicos. Cabe ressaltar que tais descritores foram validados na pesquisa realizada por Vasconcellos (2016).

$\mathrm{Na}$ figura 1 tem-se um exemplo de como uma das pesquisas organizou o eixo 1, "Estética e organização do Material Educativo. Cabe ressaltar que os números que aparecem nos campos "atende", "atende parcialmente" e "não atende" dizem respeito ao número de professores que selecionaram essas opções (Figuras 1, 2, 3 e 4). 


\begin{tabular}{|c|c|c|c|c|c|}
\hline \multirow{7}{*}{ 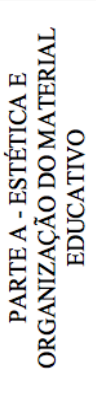 } & $\mathrm{N}^{\circ}$ & Pergunta & 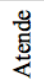 & 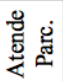 & 茎营 \\
\hline & $\mathrm{A} 1$ & Promove o diálogo entre o texto verbal e o visual. & 18 & 1 & 0 \\
\hline & A2 & Apresenta um texto atrativo e de fácil compreensão. & 18 & 1 & 0 \\
\hline & A3 & $\begin{array}{l}\text { Promove uma leitura dinâmica com informações técnicas na } \\
\text { mesma proporção com que é didático. }\end{array}$ & 18 & 1 & 0 \\
\hline & A4 & $\begin{array}{l}\text { O embasamento teórico do material está em consonância com a } \\
\text { forma escolhida para se comunicar com o leitor. }\end{array}$ & 18 & 1 & 0 \\
\hline & A5 & Tem cuidado com a escrita do texto respeitando a diversidade. & 18 & 1 & 0 \\
\hline & A6 & $\begin{array}{l}\text { O tipo de fonte e o seu tamanho da letra foram adequados para a } \\
\text { boa leitura do material. }\end{array}$ & 17 & 2 & 0 \\
\hline
\end{tabular}

Fig. 1. Extrato do instrumento avaliativo sobre Estética e organização do ME1 (Pinto \& Chisté, 2018, p. 178).

A figura 1 apresenta seis questões que orientam o leitor a formular a sua avaliação sobre o material educativo em uma perspectiva geral. Os critérios "atende", "atende parcialmente" e "não atende" visam traduzir a compreensão do grupo participante da avaliação, de forma objetiva. Ressalta-se que os instrumentos avaliativos utilizados nas diferentes pesquisas não são idênticos, sofrem ajustes e adequações, conforme a natureza e especificidade da proposta a ser analisada. Tal fato pode ser percebido no conteúdo da figura 2, na qual se observa que as questões A6 e A7 são distintas em relação à figura 1.

\begin{tabular}{|l|c|c|c|}
\hline A - ESTÉTICA E ORGANIZAÇÃO DO MATERIAL EDUCATIVO & A & AP & NA \\
\hline A1 - Promove o diálogo entre o texto verbal e o visual. & 17 & 0 & 0 \\
\hline A2 - Apresenta um texto atrativo e de fácil compreensão. & 17 & 0 & 0 \\
\hline $\begin{array}{l}\text { A3 - Promove uma leitura dinâmica com informações técnicas na mesma } \\
\text { proporção com que é didático. }\end{array}$ & 15 & 2 & 0 \\
\hline $\begin{array}{l}\text { A4 - O embasamento teórico do material está em consonância com a forma } \\
\text { escolhida para se comunicar com o leitor. }\end{array}$ & 17 & 0 & 0 \\
\hline $\begin{array}{l}\text { A5 - A fonte e o tamanho da letra foram adequados para a boa leitura do material. } \\
\text { A6 - As cores utilizadas (versão digital) foram agradáveis para a leitura do } \\
\text { material. }\end{array}$ & 17 & 0 & 0 \\
\hline $\begin{array}{l}\text { A7 - A forma como foram utilizadas as imagens possibilitou a compreensão do } \\
\text { texto. }\end{array}$ & 17 & 0 & 0 \\
\hline
\end{tabular}

Legenda: $\mathrm{A}=$ atende; $\mathrm{AP}=$ atende parcialmente; $\mathrm{NA}=$ não atende

Fig. 2. Extrato do instrumento avaliativo sobre Estética e organização do ME2 (Pinheiro \& Chisté, 2018, p. 283).

A flexibilidade do instrumento nas diferentes pesquisas fica ainda mais visível no eixo 2 , relativo à "Análise dos capítulos do material educativo". Como cada material é único, esse eixo precisa ser pensado a partir dessa singularidade. Portanto, apesar do processo avaliativo dos materiais educativos contemplar eixos comuns de análise, as especificidades de cada produção exigem a elaboração criativa e propositiva dos itens, fato que revela e marca a identidade do trabalho dos pesquisadores envolvidos. Desse modo, não defendemos como válida a formulação de um instrumento de avaliação único, genérico, padrão para avaliar todas as propostas. Apostamos na avaliação por eixos que podem ser explorados conforme as necessidades de cada objeto.

No eixo 3, "Estilo de escrita apresentado no material educativo", cada pesquisa estruturou os itens de avaliação pressupondo que a abordagem crítica de um conteúdo necessita de modos igualmente críticos e cuidadosos de exposição desse conteúdo. A figura 3 exemplifica possíveis itens de avaliação desse eixo: 


\begin{tabular}{|c|c|c|c|c|c|}
\hline \multirow{7}{*}{ 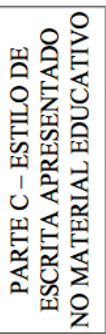 } & $\mathrm{N}^{\circ}$ & Pergunta & 营 & 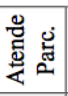 & 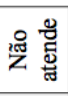 \\
\hline & $\mathrm{C} 1$ & Apresenta escrita, conceitos e argumentos claros. & 18 & 1 & 0 \\
\hline & $\mathrm{C} 2$ & Explica os termos técnicos e expressões científicas. & 16 & 3 & 0 \\
\hline & $\mathrm{C} 3$ & Estrutura as ideias facilitando o entendimento do assunto tratado. & 18 & 1 & 0 \\
\hline & $\mathrm{C} 4$ & O texto escrito é atrativo e estimula a aprendizagem do leitor. & 17 & 2 & 0 \\
\hline & $\mathrm{C} 5$ & Tem cuidado com a escrita do texto respeitando a diversidade. & 18 & 1 & 0 \\
\hline & $\mathrm{C} 6$ & $\begin{array}{l}\text { As epígrafes utilizadas no início de cada capítulo foram } \\
\text { interessantes para inspirar a leitura dos mesmos. }\end{array}$ & 17 & 2 & 0 \\
\hline
\end{tabular}

Fig. 3. Extrato de instrumento de avaliação sobre o eixo da escrita do ME1 (Pinto \& Chisté, 2018, p. 179).

O eixo 4, "Propostas didáticas apresentadas no material educativo", tal como sugerido por Leite (2019), sofreu adequações nas pesquisas do Gepech, pois os materiais educativos em análise não apresentavam atividades destinadas diretamente aos alunos. Assim, conforme Figura 4, o eixo 4 passou a ser intitulado "Conteúdo apresentado no Material Educativo", e seus descritores remeteram a possíveis adequações do conteúdo do material educativo para ser trabalhado com os alunos da educação básica, conforme podemos observar nos descritores D3, D4 e D5 da Figura 4.

\begin{tabular}{|c|c|c|c|c|c|}
\hline \multirow{6}{*}{ 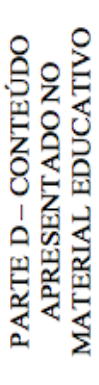 } & $\mathrm{N}^{\circ}$ & Pergunta & 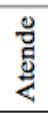 & 吾 & 学 \\
\hline & D1 & $\begin{array}{l}\text { O texto promove a leitura dinâmica, com informações técnicas na } \\
\text { mesma proporção com o que é didático. }\end{array}$ & 16 & 3 & 0 \\
\hline & D2 & Pode ser usado em processos de formação de professores. & 19 & 0 & 0 \\
\hline & D3 & O conteúdo pode ser adaptado para o Ensino Fundamental. & 16 & 3 & 0 \\
\hline & D4 & O conteúdo pode ser adaptado para o Ensino Médio. & 19 & 0 & 0 \\
\hline & D5 & $\begin{array}{l}\text { O conteúdo pode ser adaptado para a Educação de Jovens e } \\
\text { Adultos. }\end{array}$ & 19 & 0 & 0 \\
\hline
\end{tabular}

Fig. 4. Extrato de instrumento avaliativo sobre conteúdo e criticidade do EM1 (Pinto \& Chisté, 2018, p. 179).

Quanto ao eixo 5, "Criticidade apresentada no material educativo", todas as pesquisas se valeram de descritores que avaliavam o caráter provocativo do material educativo, sua fundamentação teórica, sua abordagem histórica, política e social, seu estímulo a superar crenças comuns ou hegemônicas.

\subsection{Análise das respostas à questão aberta do instrumento de validação de materiais educativos}

Como mencionado, o instrumento de validação do material educativo também deixa espaço para o leitor fazer registros complementares e enunciar outros elementos não abordados nos itens do instrumento. A análise dos dados dessa parte do instrumento assume os pressupostos da abordagem dialógica (Bakhtin, 2003), na qual os enunciados materializados na forma de textos elaborados pelos participantes ocupam um lugar de destaque no processo de avaliação e validação. Conforme Bakhtin (2003, p.307), "o texto é a realidade imediata (realidade do pensamento e das vivências)". Desse modo, o texto constitui-se como uma fonte de dados específicos e singulares que pode explicitar as impressões e críticas dos professores. A partir dessa ideia, o conjunto dos enunciados proferidos pelos docentes são lidos e analisados pelo pesquisador, o qual busca apreender recorrências de termos que produzem sentidos positivos e/ou críticos sobre 0 material educativo e que indicam possibilidades de sua reconfiguração. 
Assim, na questão aberta de cada instrumento, buscou-se apreender enunciados subjetivos e singulares não contemplados nas questões objetivas. Nessa parte, o instrumento instaurou uma abertura para que a voz do participante ultrapassasse as respostas fechadas em três alternativas e pudesse ser ouvida pelos pesquisadores.

Os dados qualitativos tiveram uma relação, ao mesmo tempo, complementar e tensa em relação aos dados quantitativos. Por um lado, confirmaram o que a seção avaliativa de traço quantitativo mapeara. Por outro, transcenderam os resultados quantitativos, inclusive, como se verá, extrapolando a avaliação do material propriamente dito. Foram várias as tendências de enunciados. A primeira delas é que, em sua grande maioria, os cursistas não sugeriram nenhuma alteração no material educativo, visto que ficaram satisfeitos com ele. Mesmo assim, quiseram registrar seus elogios e seu contentamento. Esse fato poderia ser visto como dispensável, pois essa satisfação já ficara clara nos dados quantitativos. No entanto, a insistência em registrar suas impressões positivas e elogiosas parece indicar tanto a necessidade de reforçar as respostas quantificáveis, como a insuficiência dessas quantificações. Enunciados relativos ao ME3 como "Superou as expectativas de conhecimento" (F.R.G.), "Excelente material" (J.A.P.), "[...] achei o material rico e pertinente e as discussões muito presentes na sociedade atual" (J.H.S.F.), "achei maravilhoso" (D.P.S.), extrapolam o sentido de uma simples resposta como "atende".

Para além dos elogios, os professores sentiram necessidade de expressar mudanças pessoais que experimentaram no curso. Em relação ao ME2, um participante afirmou ter experimentado "Uma nova percepção da cidade de Vitória, principalmente através da arte e dos relatos de experiência" (L.R.), enquanto outro mencionou que, com o curso e o material, houve "A possibilidade de ampliação do nosso olhar para uma cidade educativa" (M.D.S.).

A partir do nível de escolarização com o qual trabalham, os professores também avaliaram, de modo mais detalhado, as potencialidades e os limites de uso do material junto a alunos. No que concerne ao ME1, encontramos os seguintes comentários: "O Material possui uma escrita clara e didática que pode ser usado principalmente no Ensino Médio. É uma análise detalhada do processo de modernização e verticalização da cidade" (R.C.); "Considero o material eficiente e completo, necessitando apenas de adequações didáticas para o Ensino fundamental' (J.N.).

Em relação ao ME3, uma cursista registrou: "Não [tenho sugestões], achei maravilhoso. Inclusive já estou utilizando" (F.R.G.). Outra ainda vislumbrou uma nova dinâmica a ser feita com os alunos que não ocorreu na formação de professores, mas que poderia ajudar a avaliar as mudanças perceptivas acerca da cidade: "[...] fazer um prévio questionário com os alunos dos seus conhecimentos sobre a cidade, e um outro, posterior às visitas. E observar a mudança na percepção da cidade, de modo geral" (J.H.S.F.).

Também se observou a inspiração que o material oferecia para se problematizar outras cidades além de Vitória, como nas seguintes falas: "Irei propor com meus colegas da EJA uma proposta a partir do seu trabalho, mas com olhar voltado para [a cidade de] Vila Velha" (M.D.S.); "Achei completo. Me fez refletir e quero continuar refletindo a partir do meu município" (D.P.S.).

Apreciar o material tendo em vista o encontro direto com os alunos é dizer algo que escapa do contexto estrito do curso. O material educativo não teve como público alvo os alunos. No entanto, os professores cursistas indicam que ele pode ou já está ganhando vida no processo direto de ensino-aprendizagem. $\mathrm{O}$ material educativo pode ser lido por outros sujeitos ou ganhar adaptações a partir de uma nova cidade.

Apesar de poucas, as sugestões dos participantes foram ouvidas com atenção pelos pesquisadores. Por exemplo, propôs-se a alteração no tamanho da fonte utilizada no ME1 e no ME3. Um dos leitores observou que a fonte pequena dificulta a leitura. Essa observação é relevante, pois tal formatação pode prejudicar o interesse do leitor pelo texto.

Em relação ao ME1, um cursista sugeriu: "Fazer um folheto mais resumido para melhor compreensão dos alunos e não tornar a leitura um tanto quanto cansativa" (L.R.). 
Apesar de o material educativo não ter sido elaborado para ser utilizado junto aos alunos, esse comentário foi levado em consideração. As autoras ampliaram as notas explicativas e fizeram modificações que melhorassem a leitura e a compreensão. Frois e Della Fonte (2018) também optaram por introduzir um glossário para facilitar a compreensão de alguns conceitos e termos.

Houve comentários que remeteram à dinâmica do curso. Longe de serem descartados, eles foram escutados. Uma leitora recomenda, quanto ao ME3, fazer a visita mediada antes da produção artística. À primeira vista, nada impede a implementação dessa alteração, por mais que, na logística do curso, fosse relevante ir para a visita mediada já com algum aparato teórico (inclusive o artístico) que contribuísse para superar a aparência de alguns fenômenos que seriam encontrados no percurso.

Também apareceram, nos enunciados dos professores, novas problematizações. Por exemplo, uma cursista indaga: "Como pressionar as entidades públicas para cobrar uma postura mais correta da empresa [poluidora]? (J.S.E.). A partir desse comentário, Frois e Della Fonte (2018) perceberam que o material não contava com indicativos de canais de denúncias contra a poluição e crimes ambientais. Apesar de terem direcionado algumas leituras e apontado a página social da Associação dos Amigos da Praia de Camburi, faltavam maiores informações sobre os órgãos ambientais e canais de manifestação. Com base nessa indicação, eles inseriram no material alguns desses canais de denúncia e de mobilização socioambiental.

Os exemplos de enunciados destacados na questão aberta do instrumento de avaliação do material educativo revelam que houve, no próprio instrumento, o prolongamento do diálogo entre pesquisadores e cursistas não apenas sobre os E-books, mas sobre o curso como um todo, sobre mudanças pessoais e sobre projetos de trabalho de educação na cidade na escola. É a partir dessa relação dialógica produtiva (Bakhtin, 2003) que os professores participantes das pesquisas puderam oferecer suas contrapalavras e fomentar a produção de novos textos. Por essa razão, a avaliação que ocorre em um tempo presente pode comportar possibilidades de se pensar a utilização da proposta em outros contextos, com outros públicos e em outros momentos. Nessa perspectiva, embora o material apresentasse um acabamento provisório no momento da avaliação, ao mesmo tempo sugeria um inacabamento, pois abria para outras possibilidades de interlocução. Esse modo de avaliação coloca o sujeito para pensar sobre o passado, presente e futuro.

Entendemos que os instrumentos utilizados em pesquisas do Gepech, mesmo com suas especificidades temáticas, buscam alcançar esse movimento dinâmico de tempos. A avaliação, desse modo, coloca os sujeitos participantes em atividade criativa, pois estimula a potência dos sujeitos em reelaborar, revigorar e ou realimentar as expectativas. Além disso, sinaliza uma responsabilidade coletiva. Tal fato reforçou ainda mais o caráter colaborativo que envolve a construção do curso e a validação dos materiais educativos.

\section{Considerações finais}

Por mais que se inspire em experiências anteriores do âmbito da Educação Popular (Brandão, 1984), os processos de sistematização e validação de materiais educativos construídos pelo Gepech em suas investigações sobre as relações entre educação e cidade são embrionários e ainda sujeitos a aprofundamentos. Porém, em seu pouco tempo de existência, o grupo já reconhece que elaborar materiais educativos sob uma perspectiva crítica envolve um movimento duplo e articulado.

Por um lado, implica abandonar o ideário tecnicista segundo o qual especialistas elaboram materiais para os professores aplicarem.

Por outro, demanda estabelecer ações coletivas nas quais, mesmo com responsabilidades diferenciadas, os sujeitos instituem o diálogo, isto é, a interação, o reconhecimento intersubjetivo, espaço/tempo de fala/escuta, e de compromisso com a formação de todos os envolvidos. 
Essa ampla base crítica precisa ganhar materialidade no material educativo produzido. Entendemos, contudo, que o material é um produto decorrente de uma ação. Portanto, o tom problematizador e crítico precisa estar igualmente presente no resultado (nos Ebooks) e em seu processo de elaboração como um todo. Isso requer que a criticidade não esteja apenas no conteúdo que os materiais abordam, mas também no modo de produção desse material, ou seja, em todas as suas dimensões, como alerta Kaplún $(2002,2003)$. Sob essa lógica, torna-se indispensável compartilhar o material em situação concreta junto a professores, momento que não consiste em mera apresentação do material, mas parte constitutiva de sua elaboração.

Por certo, os instrumentos de avaliação desses materiais estão sujeitos a reformulações de modo a fomentar cada vez mais diálogos. Mas, esse esforço específico só ganha sentido quando as propostas de pesquisas que integram, entre outras ações, a elaboração de materiais educativos e a formação de professores, incorporarem uma abordagem ampla e crítica. Diante desses resultados, reconhecemos que o processo de criação e avaliação de materiais educativo compõe ao menos três etapas: (1) Elaboração da versão preliminar, (2) Validação, via instrumento composto por eixos de análise e descritores, realizada em colaboração com grupo representativo do público alvo, (3) Reformulação do material educativo a partir das contribuições do grupo representativo, (4) Ampla divulgação do material educativo. De modo geral, apresentamos na Figura 9, síntese de elementos desse processo.

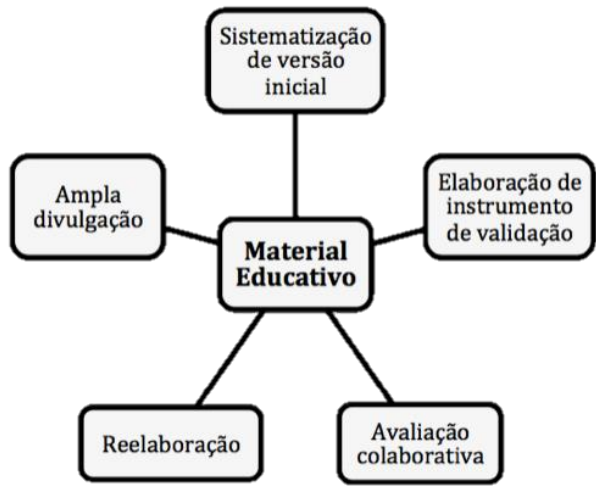

Fig. 9. Esquema do processo de produção e avaliação de materiais educativos.

Finalizamos este texto, aspirando que a proposta teórico-metodológica apresentada possa, de certo modo, estimular e orientar outros pesquisadores interessados pelo tema a produzirem e validarem materiais educativos em diferentes contextos.

\section{Referências}

Bakhtin, M. (2003). Estética da criação verbal. São Paulo: Editora Martins Fontes.

Brandão, C. R. (1984). O que é educação Popular. Editora Brasiliense.

Côco, D., Chisté, P. S., \& Della Fonte, S. S. (org.) (2018). Educação na cidade: conceitos, reflexões e diálogo. Vitória: Edifes.

Fraga, D. L., Côco, D., \& Chisté, P. de S. (2018). Educação na cidade: diálogos entre educação infantil, cidade e patrimônio cultural. Vitória, ES: Instituto Federal do Espírito Santo. Acedido janeiro 9, 2020, em https://educapes.capes.gov.br/handle/capes/552884.

Ibiapina, I. M. L. M. (2008). Pesquisa colaborativa: investigação, formação e produção de conhecimentos. Brasília: Liber Livro Editora.

Kaplún, G. (2002). Contenidos, itinerarios y juegos: tres ejes para el análisis y la construcción de mensajes educativos. VI Congreso de ALAIC - Asociación Latinoamericana de 
Investigadores de la Comunicación Santa Cruz de la Sierra, Bolivia, junio 2002 - Grupo de Trabajo: Comunicación y Educación, 01-18.

Kaplún, G. (2003). Materiais educativos: experiência de aprendizado. Revista Comunicação \& Educação, 271, 46-60.

Leite, P. S. C. (2019). Proposta de validação colectiva de materiais educativos em mestrados profissionais da área de ensino. Revista de Educación Campo Abierto, 38(2), 185-198. Acedido janeiro 9, 2020, em https://mascvuex.unex.es/revistas/index.php/campoabierto/article/view/3516. doi: 10.17398/0213-9529.38.2.185

Morais, E. R. V., \& Côco, D. (2018). Educação na cidade: diálogos possíveis para explorar a temática afro-brasileira. Vitória, ES: Instituto Federal do Espírito Santo. Acedido janeiro 9, 2020, em https://educapes.capes.gov.br/handle/capes/552963.

Frois, I. D. O., \& Della Fonte, S. S. (2018). O entorno da Vale S.A. na perspectiva do direito à cidade: da miopia verde à catarse do pó preto. Vitória, ES: Instituto Federal de Educação, Ciência e Tecnologia do Espírito Santo. Acedido janeiro 9, 2020, em https://educapes.capes.gov.br/handle/capes/552906.

Pinheiro, L. F. M. A., \& Chisté, P. S. (2018). O Parque Moscoso como espaço memória da cidade de Vitória. Vitória, ES: Instituto Federal de Educação, Ciência e Tecnologia do Espírito Santo. Acedido janeiro 9, 2020, em https://educapes.capes.gov.br/handle/capes/552952.

Pinto, P. G., \& Chisté, P. S. (2018). Educação na cidade : o processo de modernização da cidade de Vitória em debate. Vitória, ES: Instituto Federal de Educação, Ciência e Tecnologia do Espírito Santo. Acedido janeiro 9, 2020, em https://educapes.capes.gov.br/handle/capes/552894.

Ruiz, L., Motta, L., Bruno, D., Demonte, F., \& Tufró, L. (2014). Producción de materiales de comunicación y educación popular. Buenos Aires: Departamento de Publicaciones de la Facultad de Derecho y Ciencias Sociales de la Universidad de Buenos Aires.

Vasconcellos, T. V. (2016). Ciências em quadros: as contribuições da Arte Sequencial para a Educação Científica no Ensino de Ciências (Dissertação de Mestrado). Universidade Federal do Espírito Santo.

\section{Notas biográficas}

Dilza Côco. Doutora em Educação pela Universidade Federal do Espírito Santo (Ufes); Mestre em Educação pela Ufes e Licenciada em Pedagogia pela Ufes. Professora do Instituto Federal de Educação, Ciência e Tecnologia do Espírito Santo (Ifes), atua como docente no Programa de PósGraduação em Ensino de Humanidades (PPGEH) e integra o Grupo de Estudos e Pesquisas Educação na Cidade e Humanidades (Gepech).

Priscila de Souza Chisté Leite. Possui doutorado e mestrado em Educação pela Universidade Federal do Espírito Santo (Ufes). É graduada em Educação Artística pela Ufes, em Letras pelo Ifes e professora do Instituto Federal de Educação, Ciência e Tecnologia do Espírito Santo (Ifes). Atua como docente no Programa de Pós-Graduação em Ensino de Humanidades (PPGEH). É líder do Grupo de Estudos e Pesquisas sobre Educação na Cidade e Humanidades (Gepech).

Sandra Soares Della Fonte. Possui graduação em Filosofia pela Ufes (2002) e em Educação Física pela mesma universidade (1993). Fez mestrado em Educação pela Universidade Metodista de Piracicaba (1996), doutorado em Educação pela Universidade Federal de Santa Catarina (2006) e doutorado em Filosofia pela UFMG (2020). É professora da Universidade Federal do Espírito Santo desde 1997. Atua como docente no Programa de Pós-Graduação em Ensino de Humanidades (PPGEH) e integra o Grupo de Estudos e Pesquisas Educação na Cidade e Humanidades (Gepech). 